\title{
Territórios de povos e comunidades tradicionais: estado de exceção, governo bio/necropolítico e retomadas de tekoha
}

Marcos Mondardo ${ }^{1}$

\section{Resumo}

No Brasil contemporâneo existe uma geopolítica da despossessão em curso na territorialização do agronegócio de que as maiores vítimas são as populações tradicionais que ocupa(va)m seus territórios originais. As ações do Estado brasileiro e do capital têm por objetivo o desmonte, o retrocesso e a retirada dos direitos territoriais indígenas. É fundamental entender a estratégia adotada pelos povos originários para a conquista e/ou manutenção dos seus direitos territoriais. Analisamos neste texto a luta dos Guarani e Kaiowá pelo reconhecimento dos tekoha, no cone sul do Mato Grosso do Sul. Estes povos indígenas têm um projeto de autonomia na luta pela reterritorialização para o retorno ao teko porã (o bem viver) em práticas de retomadas: acampamentos, ocupações e autodemarcações. Palavras-chave: Populações tradicionais; Tekoha; Retomadas; Direitos; Autonomia.

Territories of traditional peoples and communities: State of Exception, government bio/necropolitcs and retakes of tekoha

\begin{abstract}
In contemporary Brazil, there is a geopolitics of dispossession that is taking place in the territorialization of agribusiness, that the main victims are the traditional populations that occupy their original territories. The actions of the Brazilian State and of capital are aimed at the dismantling, retraction and withdrawal of indigenous territorial rights. It is fundamental to understand the strategy adopted by the original peoples for the conquest and / or maintenance of their territorial rights. We analyze in this text the struggle of the Guarani and Kaiowá for the recognition of the tekoha, in the southern cone of Mato Grosso do Sul. These indigenous peoples have a project of autonomy in the struggle for reterritorialization for the return to teko porã (good living) in practices of retakes: camps, occupations, and self-demarcations.

Keywords: Traditional populations; Tekoha; Retakes; Rights; Autonomy
\end{abstract}

\section{Introdução}

No Brasil contemporâneo existe uma geopolítica da despossessão em curso na territorialização do agronegócio de que as maiores vítimas são as populações tradicionais que ocupa(va)m seus territórios originais. ${ }^{2}$ Esses povos e comunidades tradicionais estão envolvidos em conflitos ambientais - por terra, água, território e direitos humanos - em "r-existência"

\footnotetext{
${ }^{1}$ Universidade Federal da Grande Dourados - UFGD, Dourados - MS, marcosmondardo@yahoo.com.br

${ }^{2}$ A categoria normativa (jurídico-política) do princípio da territorialização de terra tradicional indígena foi definida no Artigo 231, § $1^{\circ}$, da Constituição Federal de 1988: "São terras tradicionalmente ocupadas pelos índios as por eles habitadas em caráter permanente, as utilizadas para suas atividades produtivas, as imprescindíveis à preservação dos recursos ambientais necessários ao seu bem-estar e as necessárias a sua reprodução física e cultural, segundo seus usos, costumes e tradições".
}

Periódico Horizontes - USF - Itatiba, SP - Brasil - e019026 
(PORTO-GONÇALVES, 2002) na luta pela "reapropriação social da natureza" (LEFF, 2006) e afirmação/valorização das identidades étnico-territoriais e coletivas (HAESBAERT, 2014). Nesse movimento antissistêmico (WALLERSTEIN, 2005) o território emerge como questão central nas lutas por redistribuição de terra (FRASER, 2002; 2006) para a construção de um ordenamento territorial pelos e para os de baixo.

É importante lembrar, segundo Porto-Gonçalves (2002), que o processo contraditório de desenvolvimento do espaço agrário da sociedade brasileira se caracteriza por relações de poder que primam pela violência e que tem como cerne a histórica concentração fundiária. Desde os anos 1970, já sob a ditadura militar (1964-1985), que uma nova fase de desenvolvimento econômico se iniciou - conhecida como "Revolução Verde" ou "Modernização Conservadora" e seus "avanços" no campo tecnológico consagraram a profunda injustiça social e a violência que subjazem a esse contraditório padrão de poder. Desde então se aprofundou um processo expropriatório de desterritorialização de camponeses, povos indígenas e quilombolas de seus territórios de uso coletivo.

No início deste século XXI o Brasil está vinculado às estruturas de dependência comercial como fornecedor de commodities agrícolas e minerais, caracterizado pelo neoextrativismo e reprimarização da economia (GUDYNAS, 2012a; 2012b; 2016). Apesar da condição por vezes assumida de global trader das exportações do setor primário brasileiro, a soja e o minério de ferro são os produtos mais dinâmicos dessa pauta exportadora e seu destino é majoritariamente o mercado chinês. Para a América do Sul, essa globalização sino-americana deixou como única opção de desenvolvimento socioespacial o aprofundamento da espoliação de suas riquezas naturais pelo neoliberalismo (HARVEY, 2004) - reforçando uma tradição que já vem desde os tempos coloniais, como analisou Eduardo Galeano (2000), em "As Veias Abertas da América Latina" - pela intensificação do uso e abuso de seus territórios.

Assim, o objetivo deste texto é analisar os conflitos territoriais contemporâneos no Mato Grosso do Sul por meio dos movimentos de luta e r-existência dos povos indígenas (Guarani e Kaiowá) pelos territórios tradicionais - tekoha - contra a territorialização do agronegócio e do governo no/do território corporativo pelo Estado de Exceção, gestão biopolítica e necropolítica.

Uma das maneiras de caracterizar os diferentes processos de desreterritorialização dos conflitos territoriais entre povos e comunidades tradicionais frente ao agronegócio é abordá-los 
a partir de categorias analíticas para a compreensão dos territórios corporativos de exceção, tais como “acumulação por espoliação" (HARVEY, 2004), povos e comunidades tradicionais (LIFSCHITZ, 2011; CARNEIRO DA CUNHA; ALMEIDA, 2009; CRUZ, 2012), regimes de expropriação de terras (LEVIEN, 2013; 2014) e cercamento dos comuns (DARDOT; LAVAL, 2014), Estado de Exceção (AGAMBEN, 2002; 2004), a gestão/governo biopolítico (FOUCAULT, 2004; 2005; 2012) e necropolítica do território (MBEMBE, 2011; 2018), desterritorialização, fragmentação, contenção, precarização territorial (HAESBAERT, 2004; 2014; 2016), redes de luta e territórios de r-existências e de vida (PORTO-GONÇALVES, 2002; 2003; 2006; ZIBECHI, 2008; 2012); tempo de acampamento (LOERA, 2014); e, a produção de multi/transterritorialidades de resistência (HAESBAERT; MONDARDO, 2010; MONDARDO, 2018).

Focalizaremos, neste trabalho, os povos e as comunidades tradicionais frente à territorialização do agronegócio no campo brasileiro, articulados ao grande capital, de corporações transnacionais e, também, de grandes grupos privados nacionais, para analisar o governo corporativo no/do território pelo Estado de Exceção, gestão biopolítica e necropolítica. Por meio da problemática do território, a partir da própria luta pela terra, propomos analisar como essa questão se tornou central no contexto brasileiro-latino-americano. Podemos distinguir pelo menos duas formas geográficas de território e multi/transterritorialidade, numa leitura mais ampla e não dualista, em que se desdobram, como sugere Haesbaert (2014), pelo menos dois grandes "paradigmas" de abordagem das questões territoriais, um que podemos denominar de hegemônico, capitaneado, sobretudo pelas grandes empresas (com o frequente apoio do Estado), e outro, contra-hegemônico, liderado pelos grupos subalternos, em nosso caso, os povos e comunidades tradicionais (indígenas).

Além de uma densa revisão bibliográfica sobre a territorialização do agronegócio no Brasil e os movimentos de resistências dos povos e comunidades tradicionais (indígenas) frente aos projetos de desenvolvimento econômicos liderados pelo setor ruralista no campo, o material empírico para esta análise foi obtido, em relação aos dados primários, por meio de órgãos do Estado (IBGE, FUNAI e SESAI, por exemplo), de relatórios produzidos pelas empresas e grandes cooperações nacionais e multinacionais, pela impressa nacional, estadual e regional, dentre outras, no sentido de sistematizar as informações referentes aos conflitos territoriais, de entrevistas que foram realizadas com sujeitos dos dois grupos sociais envolvidos, em órgãos do 
Estado e entidades não governamentais. Para os dados secundários, foram levantados e analisados os estudos acadêmicos sobre a expansão do agronegócio no Brasil, povos e comunidades tradicionais (indígenas) e o debate presente no conflito de terras, territórios e territorialidades.

Para os estudos não acadêmicos sobre a temática, realizamos um levantamento no sentimento de sistematizar a multiplicidade de posições sociais sobre a questão das lutas sociais pela terra e território. Daí a importância de trabalharmos com o tema na imprensa. Neste caso, optamos pela obtenção de dados primários junto aos jornais, revistas e ONGs, dentre outros, para identificarmos dados e informações pertinentes aos conflitos territoriais. O material empírico, com relação aos dados secundários, foi coletado por meio de trabalhos de campo em reservas indígenas, acampamentos, áreas de retomadas às margens de rodovias, em fazendas, usinas, corporações, com a realização de entrevistas (semiestruturadas), diálogos informais e amplas anotações em áreas de conflito no Mato Grosso do Sul.

\section{Populações tradicionais e conflitos territoriais em áreas de agronegócio no Brasil}

O aumento dos conflitos territoriais no campo brasileiro contemporâneo com a presença de populações tradicionais em áreas de agronegócio ocorre por meio da espoliação dos seus territórios de ocupação originária. Essas populações tradicionais (povos indígenas e comunidades quilombolas) estão envolvidas em conflitos territoriais - por terra, água, território - na luta pelo retorno ou defesa de seus territórios de ocupação e uso coletivos.

Considerando a nova configuração constitucional do país, os dados da Comissão Pastoral da Terra (CPT) revelaram que, de modo geral, o ano de 2017 deu um salto agudo de violência no campo. Foram 71 assassinados no campo em função de lutas envolvendo a questão agrária. Essa nova configuração constitucional, segundo Porto-Gonçalves (2018), agride todos os direitos das populações tradicionais. Por um lado, a "facilidade de investimento de terras para estrangeiros, por exemplo, inclusive com presença cada vez maior de grandes agentes de fundo de pensão" (p.2), que transformaram a terra em um ativo financeiro. "Então é a terra como ativo financeiro e a facilidade que o governo está dando para atrair esses investimentos (...) você tem capital disponível em mercado financeiro internacional e terras que no Brasil a gente sabe como são 
tituladas" (p.2). Essa configuração imprime um movimento arrasador de desterritorialização/prezarização dos povos indígenas, a exemplo dos Guarani e Kaiowá em Mato Grosso do Sul, pelo avanço territorial do capitalismo com seus investimentos do grande capital estrangeiro e nacional.

Conforme os dados da Comissão Pastoral da Terra, na região Centro-Oeste, o número de famílias sob a ameaça de pistoleiros quase triplicou entre 2016 e 2017, passando de 843 para 2.393, e as famílias ameaçadas de expulsão foram de 862 para 2.690. Nesta região, o estado do Mato Grosso do Sul concentrou os conflitos envolvendo indígenas. Nos conflitos por terra, as ocorrências em 2016 e 2017, são as mais elevadas desde quando a CPT começou a fazer este trabalho em 1985. Em 2016 foram 1.079 ocorrências e em 2017, 989. Números nunca atingidos nos 30 anos anteriores. Somando as 771 ocorrências de 2015, se tem uma média anual no período da ruptura política (2015-2017) de 946 ocorrências; 36,1\% maior que a média dos 10 anos imediatamente anteriores (2005-2014).

A omissão do poder público, a morosidade nos processos de regularização fundiária (a diminuição acentuada do ritmo das demarcações de Terras Indígenas no Brasil desde a última década), a contenção territorial de populações relativamente numerosas em pequenas reservas apinhadas de índios e a situação de precariedade, estão entre as violações mais praticadas contra as populações tradicionais. Segundo dados do Conselho Indigenista Missionário - CIMI (2016), existem no Brasil, 1296 pedidos de demarcações de territórios tradicionais, mas apenas 30\% estão sendo analisados.

De acordo com a Fundação Nacional do Índio - FUNAI (2016), no Brasil existiam 462 terras regularizadas que correspondem a 12,2\% do território nacional. Por região, as Terras Indígenas regularizadas estão distribuídas da seguinte maneira: 54\% estão no Norte; $19 \%$ no Centro-Oeste; $11 \%$ no Nordeste; $10 \%$ no Sul; $6 \%$ no Sudeste. ${ }^{3}$ A maior parte delas está concentrada na Amazônia Legal e esse fato é explicado pela política de integração nacional e consolidação das fronteiras norte e noroeste na década de 1980. Nas demais regiões do país, os povos indígenas foram mantidos em áreas reduzidas e esparsas, muitas delas reconhecidas pelo Serviço de Proteção ao Índio (SPI) entre os anos de 1910 e 1967, sem levar em conta os requisitos

\footnotetext{
3 “Terras indígenas, o que é?”. (FUNAI). http://www.funai.gov.br/index.php/2014-02-07-13-24-32?limitstart=0\# consultado em 05/11/2016.
}

Periódico Horizontes - USF - Itatiba, SP - Brasil - e019026 
necessários para reprodução biológica, cultural e territorial dos povos indígenas. ${ }^{4}$ De acordo com os dados da FUNAI (2016), no estado de Mato Grosso do Sul 29 terras indígenas estão regularizadas, 5 homologadas, 10 declaradas, 4 delimitadas e 15 em estudo. Essa situação territorial permite afirmar que os grupos étnicos deste estado residem em 29 Terras Indígenas, enquanto 34 Terras estão em fases de processos de regularização fundiária.

Hoje os povos e comunidades tradicionais lutam frente ao crescimento e expansão nas últimas décadas do grande projeto de desenvolvimento econômico no campo brasileiro de neoextrativismo e reprimarização, o agronegócio, articulados ao grande capital, de corporações transnacionais, bem como de grandes grupos privados nacionais. Com isso coloca-se em prática o governo no/do território corporativo pelo Estado de Exceção, gestão biopolítica e necropolítica.

É necessário, assim, ver o território como uma trama contraditória para analisar a cadeia de produção de valor como um processo não só de circulação de capital e mercadoria, mas de matéria e de energia. Esses processos metabólicos de apropriação, transformação, circulação, consumo e descarte geram uma geografia regional (CRESSWELL, 2013) dos conflitos territoriais, seja da renda da terra, do valor de uso e de troca da natureza, em áreas do agronegócio com os povos e as populações tradicionais.

\section{Os territórios tradicionais frente o Estado de Exceção e o governo bio/necropolítico}

Haesbaert (2014) afirma que nos últimos tempos a problemática do território se tornou uma questão central no contexto brasileiro-latino-americano devido à luta pela terra. O geógrafo considera que um "paradigma" ou abordagem das questões territoriais contra-hegemônicas da contemporaneidade, é aquela guiada pelos grupos subalternos, a exemplo das populações tradicionais, indígenas e quilombolas.

Para analisar esses movimentos de luta por território contra-hegêmonicos, Haesbaert (2014, p.55) propõem uma "discussão conceitual a partir da distinção, necessária, mas raramente explicitada, entre território como categoria de análise, como categoria da prática e

\footnotetext{
4 “Terras indígenas, o que é?". (FUNAI). http://www.funai.gov.br/index.php/2014-02-07-13-24-32?limitstart=0\# consultado em 05/11/2016.
}

Periódico Horizontes - USF - Itatiba, SP - Brasil - e019026 
como categoria normativa". Distinção esta, para o autor, que pressupõe analisar os sujeitos subalternos que estão envolvidos em uma questão territorial. Por isso:

A relevância em distinguirmos o conceito de território enquanto categoria de análise, categoria da prática e, também, categoria normativa. Essas formas de ler o território precisam, em certas situações, ser mais claramente distinguidas, sob pena de confundirmos (algo que é feito com relativa frequência) a utilização do termo nas práticas do senso comum, cotidianas (categoria da prática), como instrumento intelectual em nossas pesquisas (categoria de análise) e como ferramenta para a ação política, em especial o planejamento (categoria normativa). Entretanto, também não podemos cair no extremo oposto, ignorando que elas estão, frequentemente, em franco diálogo e ampla interseção (HAESBAERT, 2016, p.29-30).

Essa ampliação do conceito enquanto categoria analítica de investigação deve se dar em diálogo e interação com o uso enquanto categoria da prática e categoria normativa. Enquanto processo, essas categorias são indissociáveis da práxis efetiva e alternativa frente ao modelo hegemônico capitalista com que o território é construído, dos distintos sujeitos envolvidos e suas questões/conflitos. Devido à formação geográfico-histórica latino-americana, essas formas de pensar/construir territórios emergem nos movimentos de luta pela terra e valorização simbólicoidentitária.

Processos sintomáticos dessas transformações da relação sociedade-espaço, sobretudo na esfera dos movimentos de resistência que emergiram nas últimas duas décadas na América Latina, em países como o Brasil, o Paraguai, a Colômbia, a Bolívia, a Venezuela, a Argentina, o Uruguai, o Equador e o México, pela busca, por parte dos chamados "novos" movimentos sociais, de outras maneiras de produzir alimentos (que envolve a soberania ou segurança alimentar), e da organização em torno de outras formas de uso coletivo da terra e na gestão e apropriação dos recursos naturais.

No Brasil, indígenas, quilombolas, sem-terra, camponeses, seringueiros, ribeirinhos, cerradeiros, dentre outros, vêm questionando a ordem monopolística do Estado e afirmando territorialidades alternativas e/ou de resistência por meio de fluxos desterritorializantes que imprimem novas formas de reterritorialização, mormente, de luta, resistência e emancipação. Os povos indígenas, por exemplo, visam uma gestão de usufruto coletivo da "terra" e da "natureza" (e, em alguns casos, da "sobrenatureza", do mundo dos espíritos) e da relação com a 
sociedade para compreender outras formas, não eurocêntricas, de concepções de territórios e territorialidades. Nesse contexto, o direito ao território deve ser compreendido como um direito que condensa outras formas de direitos, sendo fundamental, para isso, concepções articuladas com os discursos e práticas (a práxis) de resistência dos sujeitos subalternos.

$\mathrm{Na}$ formação histórico-geográfica brasileira observamos que as territorialidades dos povos ou comunidades tradicionais se reinventam, hoje, tornando-se, também, num jogo interno e externo, cada vez mais múltiplas e fragmentadas em suas desreterritorializações, conflitos, estratégias e disputas dentro do/com o Estado. As reservas destinadas aos povos indígenas que foram construídas pela lógica colonial "dos hegemônicos para os subalternos", "de cima para baixo", pelo Estado brasileiro, no século XX, hoje se tornaram emblemáticas destes espaços-processos de luta contra a "territorialização" imposta. No mundo contemporâneo as lutas destes grupos étnicos para o retorno aos territórios tradicionais evidenciam a necessidade da construção de um ordenamento territorial pelos subalternos, "dos de baixo" e "para os de baixo", articulado em múltiplas escalas, da local à regional, até à nacional. Como afirmou Massey (2008, p.256), “cada luta local já é uma conquista relacional, baseada tanto dentro quanto para além do 'local', e é internamente múltipla".

No entanto, nessa necessidade de um novo ordenamento territorial para esses povos e populações, esse "governo de si", como considera Foucault (2010), pela governabilidade da vida de determinados grupos, não é um novo tipo de refortalecimento do Estado. Embora com o imperativo do controle e da vigilância estatal para com as ações destes grupos étnicos, inclusive com o racismo e o genocídio, existem resistências em curso e estratégias de luta que tornam muito mais complexa essa configuração do ordenamento territorial, pelo jogo dentro e fora, ou de inclusão por exclusão, como afirma Agamben (2002). Mesmo que precárias e de exceção, essas territorializações alternativas dos grupos étnicos em luta questionam a identidade nacional exclusivista porque evidenciam outras escalas de ordenamento, com a sobreposição territorial e múltiplas formas e conteúdos de territórios de jurisdição (normativos), das concepções e das práticas. O poder de resistência dos variados grupos indígenas, reconfigura os poderes em novas bases territoriais, a exemplo do fortalecimento das escalas local e regional.

Conhecido por seu trabalho sobre a lógica geográfica da acumulação do capital, David Harvey (2004) cunhou a expressão "acumulação por despossessão" (ou espoliação) para definir 
as práticas fundantes da busca por lucro no neoliberalismo, incluindo a financeirização, a manipulação de crises e a privatização. Essas práticas atingem de modo diferenciado cada uma das regiões econômicas do mundo, seguindo uma dinâmica geograficamente desigual de acumulação.

A “acumulação por despossessão", segundo Harvey (2011), parte do ponto de vista das transformações que o neoliberalismo impôs ao capitalismo. A princípio, a despossessão era a incorporação de regiões ainda não atingidas pelas relações capitalistas, especialmente no mundo colonial. Na era da globalização, caracterizada pela mercantilização imposta pelo neoliberalismo, por um lado, regiões novas foram incorporadas ao mercado mundial, a exemplo das regiões funcionais do agronegócio brasileiro. Nesse processo de acumulação, para Harvey, identifica-se o uso de mecanismos extra-econômicos para realização da acumulação: o roubo, a fraude e a violência.

Nesse processo, outros autores têm analisado a militarização dos territórios (GRAHAM, 2011) corporativos por meio de uma gestão necropolítica (MBEMBE, 2011; 2018) e do Estado Penal que pune os pobres (WACQUANT, 2007), entrando em vigor a espionagem e vigilância, num movimento que vai da disciplina ao controle das resistências. No Brasil, está em curso a militarização dos territórios corporativos do agronegócio pelo uso de forças armadas, policiais e de milícias que atuam de forma, por vezes, articulada, para a repressão, por meio da violência do Estado, e até a criminalização dos movimentos sociais e de seus apoiadores. Assassinatos de líderes de movimentos sociais, ambientalistas, aliados, além de intimidações e coerções se tornam a regra desse Estado de Exceção que nega os direitos socioterritoriais das populações originárias. O governo do território corporativo do agronegócio brasileiro é erigido pela conjugação do Estado de Exceção, gestão biopolítica e necropolítica. Foi erigida para isso uma nova densidade normativa do território (SANTOS, 2000) que colocou em prática a gestão/governo biopolítico, para uma política de produção de consenso e gestão social dos conflitos.

Com a expansão territorial, crescimento econômico e fortalecimento político do agronegócio no Brasil contemporâneo, o meio ambiente tem sido severamente destruído. Segundo Escobar (2014), os grandes projetos provocam rupturas/falhas metabólicas desequilíbrios que destroem as condições materiais de reprodução da vida - por meio de 
circuitos metabólicos de alta intensidade pela forte pressão material e energética sobre os ambientes biofísicos ou de alta entropia. Hoje, a agenda "ambiental" do agronegócio, com a mudança do código florestal, liberação de transgênicos e redefinição dos agrotóxicos, demonstram as contradições deste processo.

Nessa geopolítica dos territórios em disputa entre as populações tradicionais e o agronegócio, o governo do território utiliza-se de uma tecnologia política. A terra-recurso apresenta sentido econômico e político, o terreno demonstra o sentido estratégico, político e militar, e o território o sentido técnico e jurídico (ELDEN 2007; 2010). Ocorre no campo brasileiro a reestruturação dos sistemas de normas disciplinadas pelo mercado regulando e desregulando as formas de uso do território (mercantilização e comodificação). As formas de disciplinarização e controle do uso e dos fluxos dos povos e comunidades tradicionais nos territórios se manifestam por políticas de "responsabilidades" sociais e ambientais. As maneiras de controle dos sujeitos subalternos são acionadas pelas territorialidades hegemônicas pelo uso da força (militarização, repressão e encarceramento) e pelo medo (terrorismo). Assim, os conflitos territoriais ocorrem como tensão entre as formas de governo estatal e corporativa do território do grande capital e as formas populares e comunitárias de governo/gestão territorial.

\section{Territórios de defesa e luta por direitos, práticas e r-existências}

Tem se discutido no âmbito da Geografia bem como em outras Ciências Sociais, a necessidade de aprimorarmos o debate em torno do conceito de território, especialmente, pela agenda das populações tradicionais na luta, reconhecimento e afirmação dos direitos territoriais indígenas, quilombolas, camponeses e sem-terra, dentre outros sujeitos contra-hegemônicos. Os movimentos de resistência produzem a necessidade de perspectivas teóricas e metodológicas do conceito de território reelaboradas, por exemplo, pela cosmologia e/ou "ponto de vista" indígena para, assim, interagir nas lutas pela terra e valorização simbólico-identitária. Daí a importância de sólidos trabalhos de campo e de pesquisas sérias e comprometidas com a temática.

A multiplicidade de grupos étnicos no espaço brasileiro-latino-americano com diferentes processos de territorialização, línguas, relações de parentesco e movimentos de luta por direitos, 
demonstra o cuidado que devemos ter com generalizações nesse campo. Uma concepção de território, por exemplo, como tekoha é específica da cultura guarani, mas mesmo assim, apresenta variações internas e muitos indígenas preferem utilizar mais os termos "terra" e "lugar", sofrendo também nuances no seu significado a depender da cultura do grupo e dos processos de resistência e autonomia territorial em disputa.

Teorias que abrangem a sistematização do conceito de território no âmbito das dimensões sociais (cultural, econômica e política) foram realizadas, com muita propriedade na Geografia (HAESBAERT, 2004), mas parece não haver pesquisas desenvolvidas especificamente sobre concepções e práticas de território indígena. Haesbaert (2014) demonstra essa necessidade em desdobramento de trabalho seguinte. Na arte de pensar e produzir territórios, é fundamental repensar os espaços construídos pela tradicionalidade e por práticas de luta e resistência contemporânea dos povos indígenas. Para isso, destrincharemos a experiência dos povos tradicionais - indígenas, notadamente, revisitando o conceito de território na Geografia e nas Ciências Sociais, e fazendo o encontro com os conceitos nativos - como sugere Souza (2013). Tomaremos como base empírica para a análise o movimento de luta dos Guarani e Kaiowá pela retomada dos territórios antigos (tekoha) frente ao agronegócio em Mato Grosso do Sul.

No "campo verde" sul-matogrossense, as fazendas do agronegócio apresentam a territorialização hegemônica da soja, milho, cana-de-açúcar e pecuária e, contraditoriamente, com pouca vida humana. Se considerarmos, por exemplo, uma proporção entre a população do Mato Grosso do Sul estimada para 2017 em 2.713,147 habitantes segundo o IBGE (2017), o rebanho bovino do estado no mesmo ano foi de $21.824,000$ milhões de cabeça de gado, segundo levantamento da Agência Estadual de Defesa Sanitária Animal e Vegetal - IAGRO (2017), teremos um percentual de aproximadamente oito bois para cada pessoa.

Sobre essa banalização da vida, Gerber e Cardoso (2016) fazem uma analogia com o conceito foucaultiano de biopolítica (FOUCAULT, 2004) ao afirmarem que "trata-se da boipolítica [à moda das elites sul-matogrossenses], em que a vida de um boi vale mais do que a vida de um Kaiowá. Sob uma crença no Deus-mercado, é melhor exportar gado do que viver na e com a floresta" (GERBER; CARDOSO, 2016, p.01). Nessa perspectiva onipotente-onipresente mercadológica, o indígena é coisificado, desconsiderando, assim, a sua relação histórica com a terra e de resistência neste espaço. 
Do outro lado, os Guarani e Kaiowá renitentes com a imposição da disciplina em sua territorialidade circunscrita à vida nas reservas, pequenas áreas demarcadas pelo Serviço de Proteção aos Índios até 1928, colocam em prática a autodemarcação por meio das chamadas retomadas de territórios tradicionais que, hoje, transpassam seus limites, podendo ser lidas como espaço da resistência dos corpos dos vivos, mesmo que por vezes ao custo do risco efetivo de sua transformação em corpo morto. Por sua vez, os corpos mortos nas ações coletivas de retomadas desenvolvem uma relação especial e profundamente significativa com os parentes vivos, que permanecem no território reconquistado, legitimado pela morte e pelo enterro das vítimas de violência.

O drama real dessa situação é vivenciado cotidianamente pelos Guarani e Kaiowá sendo que "a morte e o morto assumem um lugar produtivo na composição dos coletivos atuais que vivem nas 'retomadas', adensando a história locais, as relações parentais e a legitimidade da luta pelo território" (MORAIS, 2016, p.40). A dor da perda de um parente se mistura com a celebração da força do coletivo, e alimenta o sentimento de irredutibilidade do desejo de viver com os parentes mortos no tekoha. O tema do morto e da morte, por isso, tem uma conectividade com o direito à terra e ao território de reconquista.

Por outro lado, a vigilância territorial no Mato Grosso do Sul integrada por sindicatos patronais, militares da reserva e da ativa, fazendeiros e juristas, e que vem profissionalizando a violência e terceirizando a gestão dos conflitos fundiários no estado, faz com que o "Estado de Exceção" (AGAMBEN, 2004) seja uma realidade pela negação cotidiana de direitos.

Agamben (2004) reconhece nessas mudanças da sociedade contemporânea um regime de "Estado de Exceção" erigido por leis de excepcionalidade que, ligadas ao poder soberano, tornam-se, hoje, a regra, pois, "inicialmente apresentadas como medidas ligadas a acontecimentos excepcionais, reservadas a situações limitadas no tempo e no espaço, tornamse regra" (p.76). Para o autor, o Estado de Exceção não mais deve ser visto como um regime adotado em uma situação circunstancial e/ou extraordinária, principalmente, empregada em um momento de emergência. Esse regime deve ser compreendido no mundo contemporâneo como uma "técnica de governo" que funciona para a "administração da vida" e, consequentemente, da própria morte, por meio da tanatopolítica. Assim como a vida, a morte é uma questão política. Foucault (2004) tratou da biopolítica, o cálculo que o poder faz sobre a vida, junto da 
tanatopolítica, cálculo do poder sobre a morte.

Na última década, o Mato Grosso do Sul liderou o ranking dos estados mais violentos contra os povos indígenas no Brasil. O Relatório de violências contra os povos indígenas no Brasil publicado pelo CIMI (2013) registrou, no ano de 2012, 53 assassinatos de indígenas no país, sendo que 33 (62\%) ocorreram no estado sul-mato-grossense. Desde 2003, são 349 homicídios, o que corresponde a 56\% do total de homicídios contra indígenas no Brasil (CIMI, 2011; 2013; 2016).

Somam-se a essa realidade dramática de mortes, os suicídios. Nos últimos dez anos segundo o CIMI (2016), 506 indígenas no Mato Grosso do Sul cometeram suicídios pelo enforcamento e foram encontrados dependurados em galhos de árvore. "Asfixia mecânica", "constrição cervical", "enforcamento", é o que está registrado nos laudos necrológicos. Estimase que mais de mil suicídios tenham ocorrido somente entre os Kaiowá e Guarani nos últimos 30 anos. As vítimas, em sua maioria, são adolescentes do sexo masculino (BRAND, 1996). A faixa etária de maior incidência é entre 15 e 19 anos entre os rapazes, e de 10 a 14 anos no sexo feminino.

Os conflitos e mortes nas reservas têm muito a ver com corpos e almas, que por sua vez compõem e decompõem na terra e com o território - indissociáveis, portanto da proliferação dos acampamentos, das retomadas, das mobilizações políticas, do parentesco, dos rituais - uma vez que implicados no próprio conceito de tekoha, assim como na busca da terra "sem males", emprega sentido à resiliência com que esses indígenas resistem à violência, à morte, ao "fim do mundo".

No conflito com os fazendeiros, os territórios Guarani e Kaiowá são produzidos pelo coração e a mente, que apresentam formas e conteúdos geográficos que se fazem e desfazem, e assim incorpora a contingência da experiência em devir do tekohahã. Com isso, a estratégia de sobrevivência é a territorialidade de luta, aquela que demarcada os territórios de resistência no front das atuais fazendas do agronegócio, mas que compõem áreas de antigos tekoha. Esse conflito territorial envolve a dinâmica espaçotemporal na compreensão e enfrentamento das situações de vulnerabilidade e conflitos fundiários (MONDARDO, 2018). Nesse movimento, as comunidades indígenas se empenham em assegurar seus direitos consuetudinários cotidianamente negados, em especial o acesso à terra. Os mortos e a tanatopolítica passam a 
ser componentes nessa luta territorial.

A gravidade da situação leva instituições de proteção aos direitos humanos e estudiosos a definirem os casos das comunidades Guarani e Kaiowá no Mato Grosso do Sul como uma grave crise humanitária. Mas existe uma face pouco observada em toda essa dramaticidade, que se refere às percepções propriamente dos indígenas:

A retomada é uma área. A gente bebe água na nascente. A gente não comia carne, não tem caça. Onde a gente vive não tem energia. Até hoje eu durmo na rede. Morar na retomada um pouco é bom, um pouco a gente se sente ameaçado. A gente mora na retomada. (...) viver na retomada é resistência. Desde os cinco anos eu moro na área de retomada, eu sei o que é viver a resistência. Na reserva não é o lugar de nós morar. Não é a nossa vida de viver. A reserva foi criada pelo Estado. O tekoha é o lugar de viver. Lá é que tem a resistência para a gente viver. (...) Retomada é para requerer nosso tekoha. A retomada é um recomeço para nós. É um recomeço para nós requerer a nossa terra, um novo começo para nós. (Kaiowá do Tekoha Guyra Kambi'y, município de Douradina/MS, entrevista realizada em 27/06/2018).

O debate sobre territorialidade e colonialidade, que impõe a "contenção territorial" (HAESBAERT, 2004) da disciplina ao controle dos "corpos dos vivos e dos mortos" (WACQUANT, 2007) a esses grupos étnicos, deve ser percebido pelas cosmologias nativas.

Em espaços coloniais como na fronteira do Brasil com o Paraguai, o racismo faz parte das bio/necropolíticas que têm regulado a distribuição de morte. Isso só é possível porque as funções repressivas do Estado se legitimam pelo encadeamento da soberania e do espaço em necroterritórios. Inspirados em Achille Mbembe estabelecemos essa correlação entre necropolítica e território. Segundo o autor, necropolítica são "as formas contemporâneas que sugam a vida ao poder da morte". Por isso, o "necropoder embaralha as fronteiras entre resistência e suicídio, sacrifício e redenção, mártir e liberdade" nas "topografias recalcadas de crueldade" (MBEMBE, 2018, p.71). Para os povos indígenas, pensamos que esses necroterritórios configuram-se em áreas de exceção de direitos e "contenção territorial" (HAESBAERT, 2008), as reservas, e em fazendas genocidas que regulam e cerceiam o ir e vir, exercem o monopólio da violência e matam. Nesse sentido, as retomadas de territórios tradicionais podem ser consideradas como práticas de um devir mundo indígena decolonial.

Se a reserva no seu sentido colonial era usada para expulsar indígenas de seus tekoha, 
influenciá-los e controlá-los por uma fronteira fechada, hoje, com as mobilizações étnicas e ações diretas de resistência de autodemarcação em retomadas territoriais, as fronteiras da reserva podem ser vistas como limites em expansão, zonas móveis e deslocáveis. Nesse sentido, as fronteiras e limites entre as reservas, acampamentos e áreas de retomadas transformaram-se no Mato Grosso do Sul, em espaços de luta (conflito) e de guerra (confronto). As cercas e limites sobrepostos/entre fazendas e tekoha separam o que se convencionou chamar, por meio do imaginário colonial, de ordem e barbárie, ou de "insegurança jurídica" (para os fazendeiros) e "insegurança social" (para os povos indígenas). Nessa visão dualista existe a negação racista do mundo indígena pela imposição das fronteiras do colonizador (não indígena).

\section{Retomadas de territórios tradicionais: acampamentos e ocupações}

A expansão territorial do capitalismo na faixa de fronteira do Brasil com o Paraguai é um fenômeno violento. Essa territorialização funcional promoveu o desmatamento, o uso ilimitado dos recursos hídricos, a violação de direitos humanos e a desterritorialização dos povos indígenas de seus tekoha. Tais populações tradicionais viram suas terras se tornarem mercadorias, em que o valor de troca suprimiu o valor de uso, implicando na mercantilização da vida por meio de uma biopolítica (a "boipolítica" à moda regional), em que as exportações de carne de gado, as toneladas de grãos (soja e milho) e os litros de etanol, valem mais do que a vida de um Guarani e Kaiowá. A biopolítica, nesta situação degradante, desterritorializa/precariza a vida indígena e a transforma em "vida nua" (conforme acepção de AGAMBEN, 2002). A mercantilização das relações sociais nesta fronteira coisificou a vida indígena como algo "sem valor" sob o vértice da hierarquia normativa das empresas multinacionais.

Gerou-se, com isso, uma geografia da acumulação de riqueza nas mãos de fazendeiros, grupos multinacionais e fundos de pensão. Estes últimos veem a terra como ativo financeiro, com investimentos nesse tipo de empreendimento em ambos os lados dos limites internacionais entre Brasil e Paraguai. A produção deste espaço regional de fronteira para o capital reproduz pobreza para as populações tradicionais, indígenas, camponeses/agricultores familiares e paraguaios. As empresas do Norte Global carecem dos recursos naturais (em que a terra e água ocupam "lugar" central) destes territórios do agronegócio para a reprodução de suas relações

$$
\text { Periódico Horizontes - USF - Itatiba, SP - Brasil - e019026 }
$$


capitalistas de produção. Isso explica o cercamento das propriedades face às reservas indígenas e à contenção territorial das ações em áreas de retomadas de territórios tradicionais.

A estabilidade territorial nesta faixa de fronteira está vinculada à segurança que o modelo de desenvolvimento econômico necessita. Por outro lado, ocorre a desterritorialização/precarização dos povos indígenas contidos e apinhados em áreas de reservas. Com o agronegócio globalizado e com o Estado neoliberal em curso, o neocolonialismo atua com força na desterritorialização dos povos Guarani e Kaiowá em seus necroterritórios. Muitos indígenas vivem em condição de miséria generalizada, sobrevivendo com cestas básicas da FUNAI (Fundação Nacional do Índio), por meio de políticas compensatórias, que expõe lógicas de "inclusão por exclusão" (AGAMBEN, 2004), legitimadas por um sistema econômico e político injusto e concentrador de riquezas.

Inconformados com esta condição de precariedade socioespacial a que foram submetidos, uma parcela de Guarani e Kaiowá colocam em prática múltiplas estratégias em fronts de luta. Estas ações diretas variam desde ocupações de áreas pelo controle temporário do espaço em acampamentos às margens de rodovias ou nas fazendas identificadas como de apropriação tradicional, até as táticas cotidianas de mobilização étnica coletiva em espaços públicos (ruas e praças) e/ou órgãos públicos (FUNAI, FUNASA, SESAI, MPF e prefeituras) (MONDARDO, 2017). As retomadas de territórios tradicionais transpassam os limites de contenção das reservas e se transformaram em espaços de luta e resistência ("um recomeço") para os povos indígenas.

Para além das reservas e dos territórios-fazendas do agronegócio com suas lógicas espaciais voltadas à contenção, violência e genocídio dos povos indígenas, os Guarani e Kaiowá contemporâneos do cone sul do Mato Grosso Sul têm um projeto de autonomia de reterritorialização de suas práticas tradicionais ancoradas no tekoha. O retorno ao teko porã (o bem viver) torna-se uma estratégia de luta por meio das retomadas de territórios tradicionais. Essas ações diretas contra a propriedade da terra, o capital e o Estado, são as formas destes povos tradicionais requererem e reviverem o tekoha. É importante frisar que a proliferação dos acampamentos de retomadas, das ocupações, das mobilizações étnico-políticas e da recriação de relações de parentesco, dos rituais e rezas de fortalecimento das lutas estão hoje implicados na própria reelaboração desta categoria da prática emancipatória indígena, o tekoha. 
Se por um lado, o Estado, articulado com o capital em sua fase neoliberal, visa manter os condenados em sua própria terra - indígenas -, territórios coloniais de exceção denominados de reservas ("sem direitos", "vida nua"), por outro, as retomadas de tekoha buscam reocupar e requerer os territórios decoloniais por meio de ações diretas de resistência e enfrentamento contra a propriedade privada na forma de latifúndio. As áreas retomadas são, hoje, territórios decoloniais que estão num limbo jurídico entre a exceção e norma do Estado de Direito, entre o latifundiário do capital legitimado pelo Estado capitalista neoliberal, e entre os territórios de autonomia e emancipação dos povos indígenas em luta. Não é a toa que o Estado considere como afirma Oliveira (2014), os indígenas que estão fora da reserva, em territorializações alternativas e ocupações, sem a sua tutela.

Nesse movimento contra o "apartheid" étnico imposto, de um lado indígenas nas reservas, do outro, brancos nas cidades e fazendas, os Guarani e Kaiowá procuram transgredir esses limites da colonialidade/modernidade (MIGNOLO, 2003; 2005) do saber e poder (QUIJANO, 2005). Articulados em múltiplas escalas de relações de poder, esses povos estão reelaborando territorialidades subalternas alternativas. A mobilização de uma parcela de Guarani e Kaiowá torna, hoje, essa categoria de população, uma poderosa biopolítica pela multiplicação das ações de resistência e enfrentamento em variadas escalas, lugares e esferas sociais.

Essa "geometria de poder" (MASSEY, 2008) das ações tenta romper com a lógica colonialista e racista que foi imposta sobre esses grupos étnicos. Como afirma Fanon (2005, p.53), "a descolonização é verdadeiramente a criação de novos homens". Nessa criação "a 'coisa' colonizada se torna homem no processo mesmo pelo qual ela se liberta". Para os povos Guarani e Kaiowá essa libertação estabelece profunda conexão com seu espaço, na medida em que a recuperação de seus territórios decoloniais, os tekoha, são indissociáveis deste movimento.

Nesse sentido, as retomadas de territórios tradicionais podem ser consideradas como práticas de um devir indígena no mundo decolonial. Essas áreas de retomadas apresentam ações mais duradouras e outras contingentes, a depender do nível do conflito e de confronto a que estão envolvidas. Estima-se que hoje proliferem mais de 40 acampamentos indígenas no estado como uma estratégia e prática concreta de luta pelo retorno aos territórios tradicionais. Mesmo sendo de difícil delimitação, com tamanhos de áreas variadas, e em sua maioria, localizados nas 
zonas rurais, o que não descarta que existam acampamentos de retomadas em espaços urbanos, o movimento de luta é territorial. Em Dourados, município epicentro de conflitos entre indígenas e fazendeiros na luta pela terra, por exemplo, encontramos os acampamentos de retomadas territoriais, Apika'y, Ñu Verã 1 e 2, Nu Porã e Pacurity, todos localizados às margens de importantes rodovias de fluxos do agronegócio do estado. Essas formas alternativas de (re)territorialização permitem aos grupos reconstruírem suas relações coletivas de apropriação, pertencimento e das territorialidades afetivo-religiosas, mesmo que em parte de seus tekoha pelo envolvimento não só de adultos e idosos, mas também de jovens e crianças indígenas nascidas em reservas, e que, hoje, retornam aos seus territórios de ocupação tradicional.

Para além das reservas e dos territórios-fazendas do agronegócio com suas lógicas espaciais voltadas à contenção, à violência e ao etnocídio dos povos indígenas, os Guarani e Kaiowá contemporâneos do cone sul do Mato Grosso Sul têm um projeto de reterritorialização de suas práticas tradicionais organizadas e mobilizadas pelo/através/do tekoha. Inconformados com a condição de precariedade socioespacial a que foram submetidos, colocam em prática múltiplas estratégias nos fronts de luta, que variam desde as ocupações de áreas pelo controle temporário do espaço em acampamentos às margens de rodovias ou em fazendas identificadas como de apropriação tradicional, até as táticas cotidianas de organização/mobilização étnica coletiva.

Por meio da reelaboração da cultura do grupo, ressignificam símbolos tradicionais/modernos e discursos na qualidade de "campos de batalha". Constroem circuitos de informação e de reprodução frente ao mercado capitalista. Desenvolvem redes espaciais multiescalares integrando várias experiências de luta local-regional que permitem pressionar o Estado, resistir e denunciar a violência e o genocídio neocolonial produzido pela sociedade capitalista do agronegócio. As práticas cotidianas de resistência, na forma de ações coletivas, possibilitam dar visibilidade às lutas em busca de autonomia e justiça sociais.

O movimento indígena promove, hoje, a ação inovadora e criadora por meio da práxis, na luta e resistência pela terra, território e pela vida. Com as condições historicamente herdadas enquanto vítimas da ocupação colonial, essas populações tradicionais fazem do movimento prático e político verdadeiramente contra-hegemônico um projeto de autotransformação. A importância das novas territorialidades dos Guarani e Kaiowá se deve à preocupação com o 
destino, com a construção do futuro, que passa pelo devir tekoha, isto é, a conquista do tekohahã.

Se o território é uma construção das relações espaço-poder, os territórios indígenas devem ser pensados e construídos por meio das relações de r-existência dos sujeitos subalternos. Como afirma Haesbaert (2014; 2016), o território ganhou uma tripla conotação no âmbito das lutas dos movimentos sociais na América Latina, assumindo uma centralidade analítica, prática e normativa, ou seja, tornou-se "categoria de análise", "categoria da práxis" e "categoria normativa". Se, de um lado, o território tem se constituído como uma categoria fundamental para repensar e reconstruir r-existências de grupos subalternos, do outro, ele tem funcionado como um dispositivo de agenciamento discursivo e prático/estratégico de grupos e/ou movimentos sociais que lutam por terra e valorização simbólico-identitária.

No caso dos Guarani e Kaiowá, o tekoha é repensado, recuperado e reocupado por uma visão de território comunal e de usufruto coletivo, que tem por base a família extensa em uma área estratégica para a vivência, garantia de reprodução e continuidade do grupo étnico. A vida no tekoha é compartilhada num sistema comunitário que busca potencializar a participação das famílias na sua organização espacial. Enquanto categoria de análise e da prática para os povos Guarani e Kaiowá, o tekoha se tornou tekohahã - em devir - um espaço de r-existência. É concomitantemente um território geográfico como epistêmico. Neste movimento de luta, o tekoha se tornou uma ação coletiva dos Guarani e Kaiowá que se mobilizam para afirmar seu discurso e de práticas de retomadas organizadas e retroalimentadas na tradicionalidade de ocupação do espaço.

\section{Considerações finais}

Para além das reservas e dos territórios-fazendas do agronegócio com suas lógicas espaciais voltadas à contenção, à violência e ao etnocídio dos povos indígenas, os Guarani e Kaiowá contemporâneos do cone sul do Mato Grosso Sul têm um projeto de reterritorialização de suas práticas tradicionais organizadas e mobilizadas pelo/através/do tekoha. Inconformados com a condição de precariedade socioespacial a que foram submetidos, colocam em prática múltiplas estratégias nos fronts de luta, que variam desde as ocupações de áreas pelo controle 
temporário do espaço em acampamentos às margens de rodovias ou em fazendas identificadas como de apropriação tradicional, até as táticas cotidianas de organização/mobilização étnica coletiva.

Por meio da reelaboração da cultura do grupo, ressignificam símbolos tradicionais/modernos e discursos na qualidade de "campos de batalha". Constroem circuitos de informação e de reprodução frente ao mercado capitalista. Desenvolvem redes espaciais multiescalares integrando várias experiências de luta local-regional que permitem pressionar o Estado, resistir e denunciar a violência e o genocídio neocolonial produzido pela sociedade capitalista do agronegócio. As práticas cotidianas de resistência, na forma de ações coletivas, possibilitam dar visibilidade às lutas em busca de autonomia e justiça sociais.

O movimento indígena promove, hoje, a ação inovadora e criadora por meio da práxis, na luta e resistência pela terra, território e pela vida. Com as condições historicamente herdadas enquanto vítimas da ocupação colonial, essas populações tradicionais fazem do movimento prático e político verdadeiramente contra-hegemônico um projeto de autotransformação. A importância das novas territorialidades dos Guarani e Kaiowá se deve à preocupação com o destino, com a construção do futuro, que passa pelo devir tekoha, isto é, a conquista do tekohahã.

Se o território é uma construção das relações espaço-poder, os territórios indígenas devem ser pensados e construídos por meio das relações de r-existência dos sujeitos subalternos. Como afirma Haesbaert (2014; 2016), o território ganhou uma tripla conotação no âmbito das lutas dos movimentos sociais na América Latina, assumindo uma centralidade analítica, prática e normativa, ou seja, tornou-se "categoria de análise", "categoria da práxis" e "categoria normativa". Se, de um lado, o território tem se constituído como uma categoria fundamental para repensar e reconstruir r-existências de grupos subalternos, do outro, ele tem funcionado como um dispositivo de agenciamento discursivo e prático/estratégico de grupos e/ou movimentos sociais que lutam por terra e valorização simbólico-identitária.

No caso dos Guarani e Kaiowá, o tekoha é repensado, recuperado e reocupado por uma memória acumulada de lutas e de cosmovisão de território comunal e de usufruto coletivo, que tem por base a família extensa em uma área estratégica para a vivência, garantia de reprodução e continuidade do grupo étnico. A vida no tekoha é compartilhada num sistema comunitário que 
busca potencializar a participação das famílias na sua organização espacial. Enquanto categoria de análise e da prática para os povos Guarani e Kaiowá, o tekoha se tornou tekohahã - em devir - um espaço de r-existência. É concomitantemente um território geográfico como epistêmico. Neste movimento de luta, o tekoha se tornou uma ação coletiva dos Guarani e Kaiowá que se mobilizam para afirmar seu discurso e de práticas de retomadas organizadas e retroalimentadas na tradicionalidade de ocupação do espaço.

\section{Referências}

AGAMBEN, G. Homo Sacer: o poder soberano e a vida nua I. Trad. Henrique Burigo. Belo Horizonte: EdUFMG, 2002.

AGAMBEN, G. Estado de exceção. Trad. Iraci D. Poleti. São Paulo: Boitempo, 2004.

AGÊNCIA ESTADUAL DE DEFESA SANITÁRIA ANIMAL E VEGETAL (IAGRO). Rebanho bovino de Mato Grosso do Sul, 2017. Disponível em: http://www.iagro.ms.gov.br/. Acesso em: 11 fev. 2018.

BRAND, A. Os suicídios entre Guarani-Kaiowá no Estado de Mato Grosso do Sul. Multitemas, Campo Grande: UCDB, n.1, p.45-53, 1996.

BRASIL. [Constituição (1988)]. Constituição da República Federativa do Brasil. Brasília, DF: Senado Federal: Centro Gráfico, 1988.

CARNEIRO DA CUNHA, M.; ALMEIDA, M. Populações tradicionais e conservação ambiental. In: CARNEIRO DA CUNHA, M. (Org.). Cultura com aspas e outros ensaios. São Paulo: CosacNaify, 2009, p.277-299.

COMISSÃO PASTORAL DA TERRA - CPT. Conflitos no campo - Brasil 2017. Goiânia: CPT Nacional - Brasil, 2017. Disponível em:

https://www.cptnacional.org.br/component/jdownloads/send/41-conflitos-no-campo-brasilpublicacao/14110-conflitos-no-campo-brasil-2017-web?ltemid=0. Acesso em: 29 dez. 2018.

CONSELHO INDIGENISTA MISSIONÁRIO - CIMI. As violências contra os povos indígenas em Mato Grosso do Sul: e as resistências do bem viver por uma terra sem males (dados 20032010). Mato Grosso do Sul: CIMI, 2011.

CONSELHO INDIGENISTA MISSIONÁRIO - CIMI. Violência contra os povos indígenas no Brasil dados de 2012. Brasília: CIMI, 2013. 
CONSELHO INDIGENISTA MISSIONÁRIO - CIMI. Violência contra os povos indígenas no Brasil dados de 2016. Brasília: CIMI, 2016.

CRESSWELL, T. Geographic thought: a critical introduction. Malden: Wiley Blackwell, 2013.

CRUZ, V. C. Povos e comunidades tradicionais. In: CALDART, R. S.; PEREIRA, I. P.; ALENTEJANO, P.; FRIGOTTO, G. (Org.). Dicionário da educação do campo. Rio de Janeiro/São Paulo: Escola Politécnica de Saúde Joaquim Venâncio/Expressão Popular, 2012, p.594-600.

DARDOT, P.; LAVAL, C. Commun: essai sur la révolution au XXle siècle. Paris: La Découverte, 2014.

ELDEN, S. Terror and Territory. Antipode, n.39, p.821-845, 2007.

ELDEN, S. Land, terra in, territory. Progress in Human Geography, v.6, n.34, p.799-817, 2010.

ESCOBAR, A. Sentipensar con la tierra: nuevas lecturas sobre desarrollo, territorio y diferencia. Medellín: UNAULA, 2014.

FANON, F. Os condenados da terra. Trad. Enilce A. Rocha e Lucy Magalhães. Juiz de Fora: EdUFJF, 2005.

FOUCAULT, M. Naissance de la biopolitique. Paris: Gallimard-Seuil, 2004.

FOUCAULT, M. Em defesa da sociedade: curso no Collège de France (1975-1976). Trad. Maria E. Galvão. 2. ed. São Paulo: Martins Fontes, 2005.

FOUCAULT, M. O governo de si e dos outros: curso no Collège de France (1982-1983). Trad. Eduardo Brandão. São Paulo: WMF Martins Fontes, 2010.

FOUCAULT, M. Ditos e escritos volume IV: estratégia, poder-saber. Trad. Vera Lúcia A. Ribeiro. 3 ed. Rio de Janeiro: Forense Universitária, 2012.

FRASER, N. A justiça social na globalização: redistribuição, reconhecimento e participação. Revista Crítica de Ciências Sociais, n.63, p.7-20, 2002.

FRASER, N. Redistribución ou reconocimiento? In: FRASER, N.; HONNETH, A. (Org.). Redistribución ou reconocimiento? Madrid: Morata, 2006.

FUNDAÇÃO NACIONAL DO ÍNDIO - FUNAI. Povos e terras indígenas. 2016. Disponível em: http://www.funai.gov.br/index.php/indios-no-brasil/quem-sao. Acesso em: 12 maio 2017.

GALEANO, E. As veias abertas da América Latina. Trad. Galeno de Freitas. 39 ed. Rio de Janeiro: Paz e Terra, 2000.

Periódico Horizontes - USF - Itatiba, SP - Brasil - e019026 
GERBER, K.; CARDOSO, J. V. Biopoder à moda das elites mato-grossenses. Disponível em: http:// outraspalavras.net/blog/2016/07/01/biopoder-a-moda-das-elites-matogrossenses/. Acesso em: 12 mar. 2017.

GRAHAM, S. Cities under siege: the new military urbanism. London/New York: Verso, 2011.

GUDYNAS, E. Estado compensador y nuevos extractivismos. Nueva Sociedad, v.237, p.128-146, 2012a.

GUDYNAS, E. O novo extrativismo progressista na América do Sul: teses sobre um velho problema sob novas expressões. LÉNA, P.; PINHEIRO DO NASCIMENTO, E. (Org.). Enfrentando os limites do crescimento: sustentabilidade, decrescimento e prosperidade. Rio de Janeiro: Garamond/IRD, 2012b, p.303-318.

GUDYNAS, E. Transições ao pós-extrativismo: sentidos, opções e âmbitos: descolonizar o imaginário. DILGER, G.; LANG, M.; PEREIRA FILHO, J. (Org.). Debates sobre pós-extrativismo e alternativas ao desenvolvimento. São Paulo: Fundação Rosa Luxemburgo, 2016, p.174-212.

HAESBAERT, R. O mito da desterritorialização: do "fim dos territórios" à multiterritorialidade. Rio de Janeiro: Bertrand Brasil, 2004.

HAESBAERT, R. Sociedades biopolíticas de in-segurança e des-controle dos territórios. In: OLIVEIRA, M. et al. (Org.). O Brasil, a América Latina e o mundo: espacialidades contemporâneas. Rio de Janeiro: Lamparina/Faperj/ANPEGE. 2008.

HAESBAERT, R. Viver no limite: território e multi/transterritorialidade em tempos de insegurança e contenção. Rio de Janeiro: Bertrand Brasil, 2014.

HAESBAERT, R. Armadilhas do território. In: BORZACCHIELLO DA SILVA, J.; SILVA, C. N.M.; DANTAS, E. W. C. (Org.). Território: modo de pensar e usar. Fortaleza: EdUFC, 2016, p.19-42.

HAESBAERT, R.; MONDARDO, M. Transterritorialidade e antropofagia: territorialidades de trânsito numa perspectiva brasileiro-latino-americana. GEOgraphia, n.24, p.19-50, 2010.

HARVEY, D. O novo imperialismo. Trad. Adail Sobral e Maria S. Gonçalves. São Paulo: Loyola, 2004.

HARVEY, D. O enigma do capital: e as crises do capitalismo. Trad. João Alexandre Peschanski. São Paulo: Boitempo, 2011.

INSTITUTO BRASILEIRO DE GEOGRAFIA E ESTATÍSTICA (IBGE). Cidades e Estados do Brasil, 2017. Disponível em: https://cidades.ibge.gov.br/. Acesso em: 11 fev. 2018.

LEFF, E. Racionalidade ambiental: a reapropriação social da natureza. Trad. Luis Carlos Cabral. Rio de Janeiro: Civilização Brasileira, 2006. 
LEVIEN, M. Regimes of dispossession: from steel towns to special economic zones.

Development and Change. v.44, n.2, p.381-407, dez. 2013.

LEVIEN, M. Da acumulação primitiva aos regimes de desapropriação. Sociologia \& Antropologia, Rio de Janeiro, v.4, n.1, p.21-53, jun.2014.

LIFSCHITZ, J. A. Comunidades tradicionais e neocomunidades. Rio de Janeiro: Conta Capa, 2011.

LOERA, N.R. Tempo de acampamento. São Paulo: Editora UNESP, 2014.

MASSEY, D. Pelo espaço: uma nova política da espacialidade. Trad. Hilda P.Maciel e Rogério Haesbaert. Rio de Janeiro: Bertrand Brasil, 2008.

MBEMBE, A. Necropolítica. Tenerife: Melusina, 2011.

MBEMBE, A. Necropolítica: biopoder, soberania, estado de exceção, política da morte. Trad. Renata Santini. São Paulo: n-1, 2018.

MIGNOLO, W. Histórias locais/projetos globais: colonialidade, saberes subalternos e pensamento liminar. Belo Horizonte: UFMG, 2003.

MIGNOLO, W. A colonialidade de cabo a rabo: o hemisfério ocidental no horizonte conceitual da modernidade. In: LANDER, E (Org.). A colonialidade do saber: eurocentrismo e ciências sociais: perspectivas latino-americanas. Buenos Aires: CLACSO, 2005, p.8-23.

MONDARDO, M. Insecurity territorialities and biopolitical strategies of the Guarani and Kaiowá indigenous folk on Brazil's borderland strip with Paraguay. L'Espace Politique, n.31, 2017. Disponível em: http://espacepolitique.revues.org/4212. Acesso em: 27 nov. 2017. DOI: 10.4000/espacepolitique.4212.

MONDARDO, M. Territórios de trânsito: dos conflitos entre Guarani e Kaiowá, paraguaios e "gaúchos" à produção de multi/transterritorialidades na fronteira. Rio de Janeiro: Consequência, 2018.

MORAIS, B. M. Do corpo ao pó: crônicas da territorialidade Kaiowá e Guarani nas adjacências da morte. São Paulo: Elefante, 2016.

OLIVEIRA, J. P. Pacificação e tutela militar na gestão de populações e territórios. MANA, v.20, n.1, p.125-161, 2014.

PORTO-GONÇALVES, C. W. Da geografia às geo-grafias: um mundo em busca de novas territorialidades. In: SADER, E.; CECENA, A. E. (Org.). La guerra infinita-hegemonia y terro mundial. Buenos Aires: CLACSO, 2002, p.217-253. 
PORTO-GONÇALVES, C. W. A geograficidade do social: uma contribuição para o debate metodológico sobre estudo de conflito e movimentos sociais na América Latina. In: SEONE, J. (Org.). Movimientos sociales y conflito em América Latina. Buenos Aires: CLACSO, 2003, p.141150.

PORTO-GONÇALVES, C. W. A reinvenção dos territórios: a experiência latino-americana e caribenha. In: CECEÑA, A. E. (Coord.). Los desafíos de las emancipaciones en un contexto militarizado. Buenos Aires: CLACSO, 2006, p.151-197.

PORTO-GONÇALVES, C. W. Conflitos no campo mostram nova configuração constitucional do país. Disponível em: https://www.brasildefato.com.br/2018/06/05/conflitos-no-campomostram-nova-configuracao-constitucional-do-pais-afirma-professor/index.html. Acesso em: 13 jun. 2018.

QUIJANO, A. Colonialidade do poder, eurocentrismo e América Latina. In: LANDER, E. (Org.). A colonialidade do saber: eurocentrismo e ciências sociais: perspectivas latino-americanas. Buenos Aires: CLACSO, 2005, p.107-130.

SANTOS, M. Por uma outra globalização: do pensamento único à consciência universal. São Paulo: Record, 2000.

SOUZA, M. L. Os conceitos fundamentais da pesquisa sócio-espacial. Rio de Janeiro: Bertrand Brasil, 2013.

WACQUANT, L. Punir os pobres: a nova gestão da miséria nos Estados Unidos. Trad. Sérgio Lamarão. Rio de Janeiro: Revan, 2007.

WALLERSTEIN, I. O que significa hoje ser um movimento anti-sistêmico. In: LEHER, R. SETÚBAL, M. Pensamento crítico e movimentos sociais. São Paulo: Cortez, 2005, p.263- 276.

ZIBECHI, R. Territorios en resistência: cartografía política de las periferias urbanas latinoamericanas. Argentina: La Vaca, 2008.

ZIBECHI, R. Brasil Potência: entre a integração regional e um novo imperialismo. Trad. Carlos W. Porto-Gonçalves. Rio de Janeiro: Consequência. 2012.

Recebido em janeiro de 2019.

Aprovado em janeiro de 2019.

Periódico Horizontes - USF - Itatiba, SP - Brasil - e019026 